\title{
Spontaneous release of interferon $\gamma$ by intestinal lamina propria lymphocytes in Crohn's disease. Kinetics of in vitro response to interferon $\gamma$ inducers
}

\author{
S Fais, M R Capobianchi, F Pallone, P Di Marco, M Boirivant, F Dianzani, A Torsoli
}

\begin{abstract}
The spontaneous induced release of interferon $\gamma($ IFN $\gamma)$ by cultured intestinal lamina propria lymphocytes was investigated in patients with Crohn's disease. In contrast to normal lymphocytes, intestinal lymphocytes from these patients spontaneously released IFN $\gamma$ and seemed to contain IFN $\gamma$ in their cytoplasm. Autologous peripheral lymphocytes did not release IFN $\gamma$. When stimulated with interferon inducers lamina propria lymphocytes from Crohn's disease tissue showed an increase in IFN $\gamma$ release 24 hours after induction with no appreciable further increase over the next two days of culture, while in control cells, either peripheral or intestinal, IFN $\gamma$ release progressively increased, peaking 72 hours after induction. These findings indicate that in Crohn's disease the intestinal lymphocytes are stimulated in vivo to produce IFN $\gamma$ and that the spontaneous IFN $\gamma$ production is compartmentalised to the gut lymphocytes. These data support the concept that locally released IFN $\gamma$ has a crucial role in cell interactions in the lamina propria and contribute to the locally occurring immune phenomena in Crohn's disease, including the increased epithelial expression of major histocompatibility complex class II antigens.
\end{abstract}

Interferon $\gamma$ and (IFN $\gamma$ ) is a cytokine which has a central role in the regulation of immune response in humans. ${ }^{1}$ The production of IFN $\gamma$ is a specialised function of $\mathrm{T}$ lymphocytes which are capable of releasing IFN $\gamma$ in response to a variety of stimuli. ${ }^{2}$ The IFN $\gamma$ inducers may activate $T$ cells in either a polyclonal or a clonally restricted manner ${ }^{2}$ and this effect seems to be dependent on the generation of an adequate amount of the lymphokine interleukin 2 (IL-2). ${ }^{3-4}$ The effects of IFN $\gamma$ involve the enhancement of several functions of lymphocytes and phagocytes and the induction and modulation of major histocompatibility complex class II antigens on different cell types.

Crohn's disease is characterised by a chronic active immune mediated inflammatory response in the intestinal wall. Several immunological abnormalities, either humoral or cellular, have been described in the peripheral blood of such patients and local immune mechanisms have been shown to occur in the affected gut mucosa. ${ }^{6}$ Intestinal lamina propria mononuclear cells in Crohn's disease are an activated cell population showing increased expression of activation antigens, ${ }^{7}$ increased spontaneous secretion of immunoglobulins, ${ }^{8}$ and increased chemotactic activity. ${ }^{9}$ Mucosal epithelium from the inflamed areas shows an increased expression of major histocompatibility complex class II antigens. ${ }^{10}$ Furthermore, class II antigens can be induced in vitro on cultured normal human intestinal epithelial cells by the addition of recombinant IFN."

It therefore seemed conceivable that in Crohn's disease there is local production of IFN $\gamma$ in the intestinal mucosa. To test this hypothesis the spontaneous and the (polyclonally) induced release of IFN $\gamma$ in Crohn's disease and control lamina propria mononuclear cells was investigated. The kinetics of the response of the lamina propria mononuclear cells to IFN $\gamma$ inducers was also studied, as well as the occurrence of IFN $\gamma$ containing cells in the intestinal lamina propria of these patients.

\section{Methods}

\section{ISOLATION OF LAMINA PROPRIA MONONUCLEAR} CELLS

Mucosal samples were obtained from the affected areas of surgical specimens of nine patients with Crohn's disease of the colon. The disease was active in all patients as defined by clinical and laboratory parameters ${ }^{12}{ }^{13}$ and the indication for surgery was the failure of medical treatment in all patients. The histology of the resected specimens showed the typical pattern of Crohn's disease. ${ }^{14}$ Areas contiguous to the specimens used for the study showed active inflammatory changes in both the mucosa and submucosa. For control samples, samples, from the macroscopically and microscopically unaffected areas of seven resected specimens were used (five colonic cancer, one diverticular disease, one severe chronic constipation). In none of these samples was there histological evidence of inflammation.

The colonic mucosa was dissected within one hour of resection and lamina propria mononuclear cells were isolated using the DTT-EDTAcollagenase method. ${ }^{715}$ Strips of the mucosa (8-9 g total weight) were washed in Hanks's balanced salt solution free of calcium and magnesium (HBSS-CMF) (Flow Lab). They were then washed in HBSS-CMF containing $1 \mathrm{mM}$ of dithiothreitol (DDT) (Sigma Chem) and antibiotics (penicillin $100 \mathrm{U} / \mathrm{ml}$, streptomycin $100 \mu \mathrm{g} / \mathrm{ml}$, gentamicin $50 \mu \mathrm{g} / \mathrm{ml}$, and amphotericin $25 \mu \mathrm{g} / \mathrm{ml}$ ) for 15 minutes at room temperature. After three washings in HBSSCMF the mucosal strips were chopped into pieces of approximately $3 \times 3 \mathrm{~mm}$. These tiny pieces were then incubated four or five times in HBSS-CMF containing $0.75 \mathrm{mM}$ ethylenedi- 
amine tetra-acetic acid (EDTA), $10 \mathrm{mM}$ Hepes buffer, and antibiotics for $45 \mathrm{~min}$ at $37^{\circ} \mathrm{C}$ in a humid $5 \% \mathrm{CO}_{2}$ atmosphere to remove epithelial cells. After two washes the pieces were incubated for $10-13$ hours at $37^{\circ} \mathrm{C}$ in a humid $5 \% \mathrm{CO}_{2}$ atmosphere in complete medium containing $25 \mathrm{U} / \mathrm{ml}$ purified collagenase (CLSPA, Worthington).

The supernatant was then collected and washed twice in HBSS-CMF and the pellet resuspended in complete medium and layered on a Ficoll-Paque density gradient. The resulting lamina propria mononuclear cells were counted and checked for viability using $0 \cdot 1 \%$ trypan blue (viability ranged from 85-95\%). Autologous peripheral blood mononuclear cells were obtained from venous heparinised blood layered on a Ficoll-Paque density gradient.

\section{ASSESSMENT OF IL-2 RECEPTOR (IL-2R) POSITIVE CELLS}

The expression of IL-2R by freshly isolated lamina propria and peripheral blood mononuclear cells from Crohn's disease and control specimens was checked by indirect immunofluorescence using an anti-IL-2R monoclonal antibody (Becton-Dickinson, USA) as previously described. ${ }^{7}$ Briefly, both types of cells were incubated for 30 minutes at $4^{\circ} \mathrm{C}$ at the concentration of 1 million cells/200 $\mu$ l with the IL-2R monoclonal antibody (undiluted). After two washings in HBSS-CMF the aliquots of cells were incubated for 30 minutes at $4^{\circ} \mathrm{C}$ with a goatantimouse IgG fluorescein isothiocyanate conjugate (Becton-Dickinson) diluted 1:20 in phosphate buffered saline ( 1 million cells in $100 \mu$ of the diluted antibody). After two washings in HBSS-CMF cells were examined under a Laborlux 12 Leitz fluorescence microscope. At least 200 cells for each aliquot were counted and checked for fluorescence. The percentage of cells positive for IL-2R was assessed in each duplicate experiment.

\section{CULTURES OF MONONUCLEAR CELLS}

Lamina propria and peripheral blood mononuclear cells were resuspended in complete medium at a concentration of $1 \times 10^{6} \mathrm{cells} / \mathrm{ml}$ and cultured in flat bottomed 24 well culture plates (Falcon Plastic) with and without the initial addition of either phytohaemagglutinin $(2 \mu \mathrm{g} / \mathrm{ml})$ or straphylococcal enterotoxin B $(0.5 \mu \mathrm{g} / \mathrm{ml})$. After $12,24,48$, and 72 hours culture supernatants were collected and stored at $-80^{\circ} \mathrm{C}$.

INTERFERON TITRATION AND CHARACTERISATION Interferon was measured and characterised in culture supernatants at $12,24,48$, and 72 hours. Interferon titre was determined by inhibition of Sindbis virus haemagglutinin yield after a single growth cycle as previously described.$^{16}$ Briefly, serial dilutions $(0.5 \mathrm{log}$ ratio) of supernatants were added to triplicate wells of human amnion Wish cells and incubated overnight. Dilutions were then removed and the culture rinsed and challenged with Sindbis virus at multiplicity of infection of 100:1. Twenty four hours later the protection from viral replication was determined by cytopathic effect reading and by titration of virus yield, measured by haemagglutination with goose red cells. In each titration a preparation of standard interferon (NIH Gg 23-901-530) was run and the titres were adjusted, when needed, to the standard value. Usually this was not necessary, since in our system 1 unit of the international standard gives $0.5 \mathrm{log}$ of viral inhibition, corresponding to full sensitivity of the assay system. Interferon activity was expressed as $\log 10$ of $\mathrm{IU} / \mathrm{ml}(\log \mathrm{IU} / \mathrm{ml})$. Representative interferon samples were characterised as $\gamma$ type by acid treatment and neutralisation with specific antibodies (polyclonal antiIFN $\alpha$, Shering; polyclonal anti-IFN $\beta$, Sclavo; monoclonal anti-IFN $\gamma$, Hoffman-La Roche) as previously described. ${ }^{17}$

\section{INDIRECT IMMUNOFLUORESCENCE FOR IFN $\gamma$} CONTAINING CELLS

Unstimulated lamina propria mononuclear cells from Crohn's disease patients and phytohaemagglutinin stimulated lamina propria and peripheral blood mononuclear cells from control specimens were treated with $0.01 \%$ Triton $\mathrm{X}$ 100 (Sigma Chem) for 30 minutes at room temperature in RPMI 1640 to allow the cells to take up the antibody within the cytoplasm. After washing in HBSS-CMF cells were subjected to trypan blue exclusion, resuspended, and incubated at a concentration of 1 million/200 $\mu$ with an anti-IFN $\gamma$ monoclonal antibody (Hoffman-La Roche) diluted 1:30 for 30 minutes at $4^{\circ} \mathrm{C}$. After two washings with HBSS-CMF the aliquots of cells were incubated for 30 minutes at $4^{\circ} \mathrm{C}$ with a goat-antimouse IgG fluorescein isothiocyanate conjugate (Becton-Dickinson). Cells were washed twice with HBSS-CMF and examined under a Laborlux 12 Leitz fluorescence microscope. At least 200 cells for each aliquot

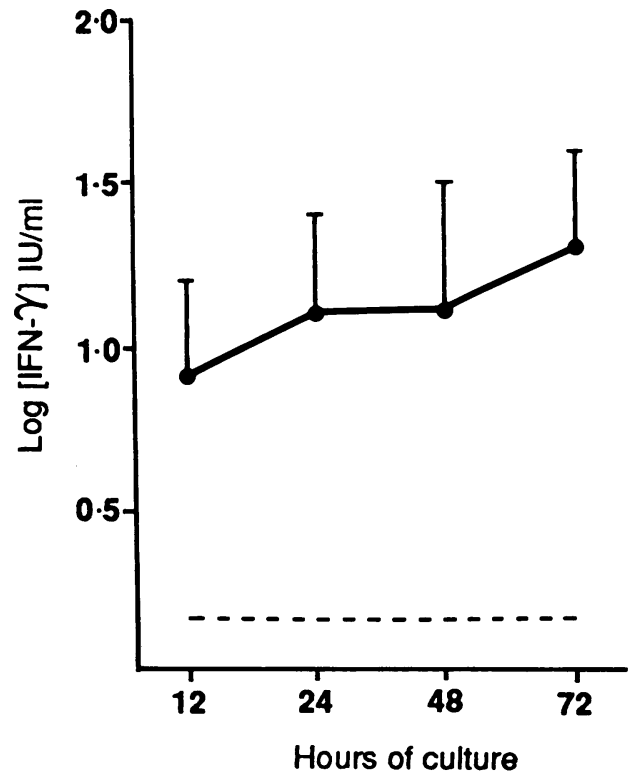

Figure 1: Kinetics of the spontaneous in vitro release of IFN by cultured lamina propria mononuclear cells from Crohn's disease (solid line) and control (broken line) intestine. Each point on the curve is the mean of all experiments. Vertical bars represent 1 SEM. 
were counted and checked for fluorescence. The percentage of cells with cytoplasmic or membrane positivity was assessed in each duplicate experiment.

\section{STATISTICAL ANALYSIS}

The non-parametric two tailed Wilcoxon's rank sum test and Student's $t$ test were used as appropriate for the statistical analysis of the data.

\section{Results}

No interferon was detected in the culture supernatants of unstimulated lamina propria and peripheral blood mononuclear cells from the control group. Similarly, no measurable interferon was found in the cultures of peripheral blood mononuclear cells from Crohn's disease patients. In contrast, interferon was found and characterised as $\gamma$ in all the Crohn's disease lamina propria mononuclear cell unstimulated culture supernatants at each time interval, with mean (SEM) concentrations ranging from 0.9 $(0.3)$ (median 0.75$)$ at 12 hours to $1.3(0.3)$ (median 1.25) at 72 hours (Fig 1). As shown in Figure 1 the release of IFN $\gamma$ by these cells was fairly stable over the culture period.

When cultures were stimulated with the specific IFN $\gamma$ inducers staphylococcal enterotoxin B or phytohaemagglutinin the release of IFN $\gamma$ by Crohn's disease lamina propria mononuclear cells was significantly higher $(\mathrm{p}<0.05)$ than that at each time interval by unstimulated Crohn's lamina propria cells. As shown in Figures 2 and 3, however, the release of IFN $\gamma$ induced by both staphylococcal enterotoxin B and phytohaemagglutinin increased 24 hours after induction compared with the 12 hour value (mean (SEM) $1.9(0.3) v 1.5(0.3)$ with staphy-

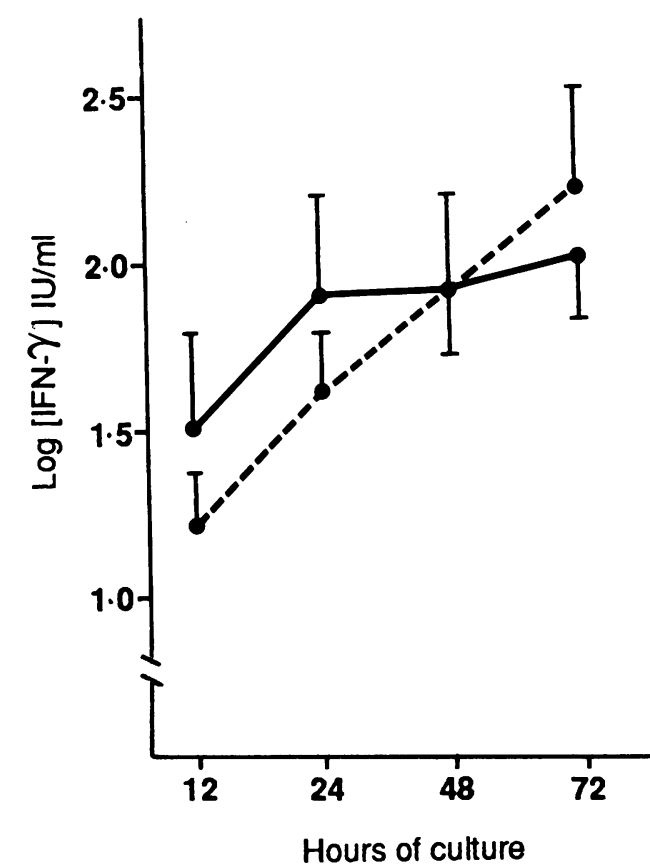

Figure 2: Kinetics of the staphylococcal enterotoxin $B$ induced in vitro release of IFN $\gamma$ by cultured lamina propria mononuclear cells from Crohn's disease (solid line) and control (broken line) intestine. Points on the curves are the means of all experiments. Vertical bars represent 1 SEM.

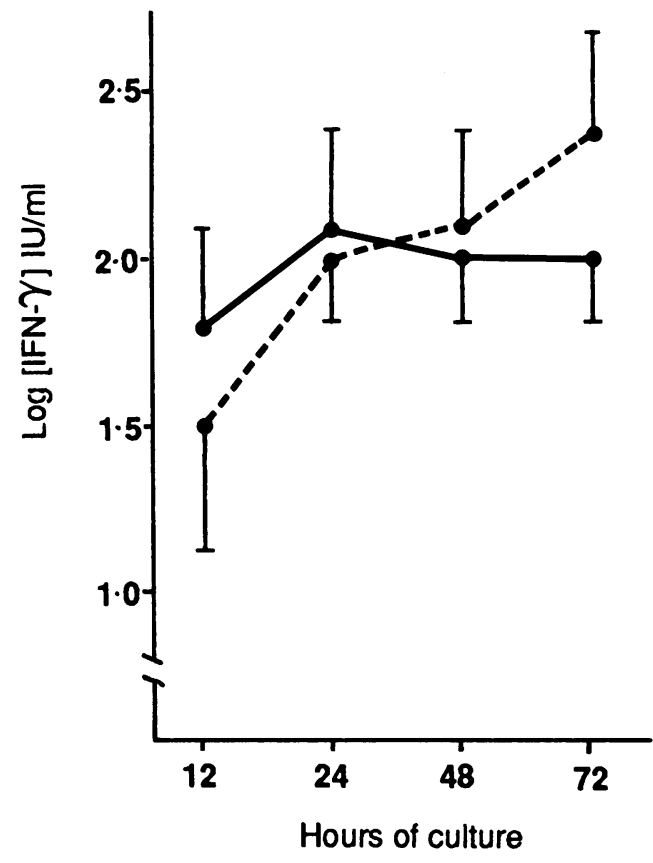

Figure 3: Kinetics of the phytohaemagglutinin induced in vitro release of IFN $\gamma$ by cultured lamina propria mononuclear cells from Crohn's disease (solid line) and control (broken line) intestine. Points on the curves are the means of all experiments. Vertical bars represent 1 SEM.

lococcal enterotoxin B and $2 \cdot 1(0 \cdot 3) v 1 \cdot 8(0 \cdot 2)$ with phytohaemagglutinin), but no further increase was observed over the culture period.

After stimulation with either staphylococcal enterotoxin B or phytohaemagglutinin a prompt response of lamina propria mononuclear cells from control tissues was seen. These cells appeared to release a substantial amount of IFN $\gamma$ as early as 12 hours after culture $(1 \cdot 2(0 \cdot 2)$ median 1.5 and $1.5(0.4)$ median 1.8 respectively). In contrast to Crohn's disease lamina propria mononuclear cells the amount of IFN $\gamma$ released by control lamina propria cells progressively increased over the culture period and reached a peak after 72 hours (staphylococcal B $2 \cdot 2(0 \cdot 3)$ median $2 \cdot 5$; phytohaemagglutinin $2 \cdot 4$ $(0.4)$ median $2.5, \mathrm{p}<0.05 v 12,24$, and 48 hours) (Figs 2 and 3).

Similarly, peripheral blood mononuclear cells from both Crohn's disease patients and control specimens were induced to release IFN $\gamma$, and the amount released progressively increased from the first 12 hours to the third day of culture (Crohn's disease staphylococcal enterotoxin B: $1 \cdot 7(0 \cdot 2), 2 \cdot 0(0 \cdot 2), 2 \cdot 3(0 \cdot 1), 2 \cdot 3(0 \cdot 1)$; phytohaemagglutinin: $1 \cdot 7(0 \cdot 2), 1 \cdot 9(0 \cdot 1), 2 \cdot 4(0 \cdot 4)$, $2 \cdot 4(0.4)$; controls $1 \cdot 7(0 \cdot 3), 2 \cdot 2(0.3), 2 \cdot 5(0.3)$, $2 \cdot 6(0 \cdot 1)$ and $1.5(0.2), 1.6(0 \cdot 1), 2 \cdot 3(0.2), 2 \cdot 4$ $(0 \cdot 1))$.

The proportion of IL-2R bearing lamina propria mononuclear cells in Crohn's disease was significantly higher than that of autologous peripheral blood mononuclear cells and that of control lamina propria and peripheral blood cells (21 (6)\%, $6(2) \%, 9(4) \%$, and $1(0.5) \%$ respectively, $\mathrm{p}<0.01)$.

After permeabilisation 18 (2)\% of the unstimulated Crohn's disease lamina propria cells showed an intense cytoplasm fluorescence (Fig 4) with a monoclonal antibody anti-IFN $\gamma$, while unstimulated control lamina propria and 


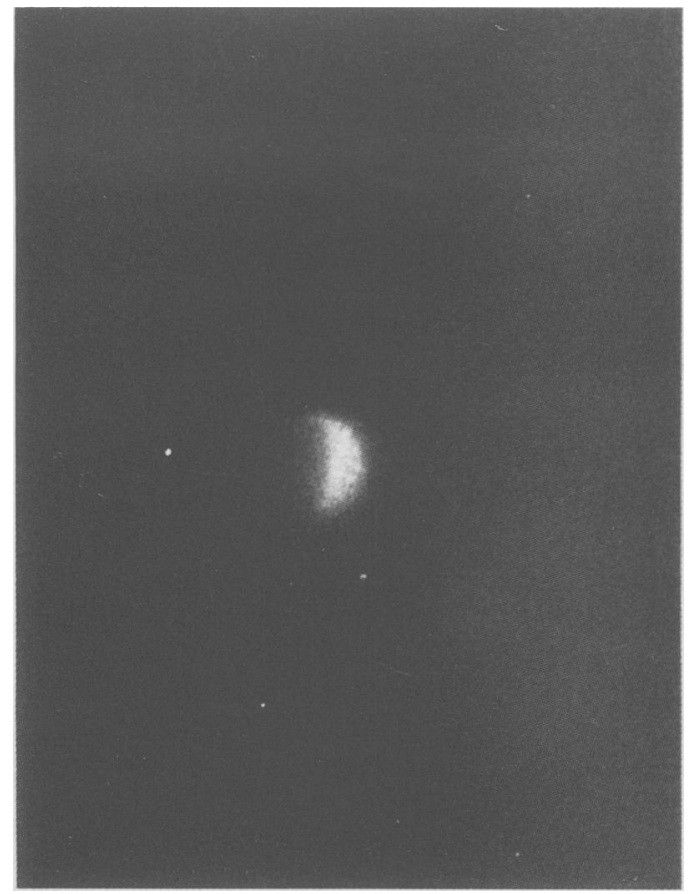

Figure 4: Immunofluorescence picture showing the cytoplasmic staining of an isolated lamina propria mononuclear cells reacting with the anti IFN $\gamma$ monoclonal antibody $(\times 900)$.

peripheral blood cells and Crohn's disease peripheral blood cells did not seem to react. After 72 hours of mitogen stimulation the following percentages of cells reacted with the antiIFN $\gamma$ monoclonal antibody; 14 (2)\% among the control lamina propria cells, $11(2) \%$ among the Crohn's disease peripheral blood cells, and 10 (1)\% among the control peripheral blood cells. The type of fluorescence did not differ between unstimulated and mitogen stimulated lamina propria mononuclear cells. None of the cells in either population of lamina propria or peripheral blood mononuclear cells appeared to react with the anti-CD3 monoclonal antibody after Triton $\mathrm{X}-100$ treatment.

\section{Discussion}

The present study shows that lymphocytes from the intestinal lamina propria of Crohn's disease patients are capable of releasing IFN $\gamma$ spontaneously and that when freshly isolated from the inflamed mucosa these cells contain IFN $\gamma$ in the cytoplasm. This study also shows that in response to polyclonal activation normal human intestinal lymphocytes produce IFN $\gamma$ similarly to autologous peripheral lymphocytes, suggesting that they are fully responsive. The response to IFN $\gamma$ inducers by Crohn's disease lamina propria mononuclear cells seems to differ from that of both autologous peripheral blood and control lamina propria mononuclear cells. In fact, lamina propria cell from Crohn's disease, when stimulated with different $T$ cell mitogens, showed a maximal IFN $\gamma$ release 24 hours after induction, with no significant further increase over the two days of culture. In contrast, control cells - either peripheral or intestinal - showed a progressive increase of IFN $\gamma$ release which peaked at 72 hours after induction. These find- ings are apparently in conflict with data reporting defective production of IFN $\gamma$ by lamina propria mononuclear cells in inflammatory bowel disease after in vitro stimulation. ${ }^{18}$ Our kinetics experiments showed that IFN $\gamma$ production by Crohn's disease lamina propria cells was higher than that of control specimens early in the culture and declined over the next two days of culture. This indicates that in Crohn's disease intestinal lymphocytes are already stimulated 'in vivo' to produce IFN $\gamma$ and are less responsive to in vitro' further stimulation. It is also possible that part of the interferon spontaneously released at the beginning of the culture was inactivated over the three day culture as a consequence of the temperature related poor stability of interferon. ${ }^{19}$ This may partially account for the type of kinetics of interferon release observed with Crohn's lamina propria mononuclear cells.

Crohn's disease peripheral blood mononuclear cells did not spontaneously produce IFN $\gamma$ and the kinetics of response to IFN $\gamma$ inducers did not differ from that of both control lamina propria and peripheral blood cells. Thus, the IFN $\gamma$ production in Crohn's disease seems to be restricted to cells locally involved in the inflammatory process in the gut. The compartmentalisation of spontaneous IFN $\gamma$ production has also recently been shown in lung $\mathrm{T}$ cells in patients with pulmonary sarcoidosis. ${ }^{20}$

The epithelium of actively inflamed mucosa expresses HLA-DR antigens, ${ }^{1021}$ and we have shown that this expression is related to an increased number of activated lamina propria lymphocytes. ${ }^{10}$ We have also shown that IFN $\gamma$ can induce HLA-DR antigens ${ }^{11}$ and other molecules $^{22}$ on normal human intestinal epithelial cells 'in vitro'. Furthermore, in experimental animals evidence has been provided that major histocompatibility complex class II antigen expression on intestinal epithelium is modulated by supernatants of intraepithelial lymphocytes containing IFN $\gamma$ like activity. ${ }^{23}$ The results of the present study showing that lamina propria mononuclear cells of Crohn's disease are an activated population and spontaneously produce IFN $\gamma$ suggest that this IFN $\gamma$ may be responsible for the increased HLA-DR antigens on intestinal epithelium in this condition. ${ }^{11}$ Whether this IFN $\gamma$ induced increase in the epithelial majorhistocompatibility complex class II antigen expression necessarily implies that these cells are able to act as antigen presenting cells is not fully understood. ${ }^{1124-25}$ It is also not known whether other biological functions of IFN $\gamma^{26}$ are exerted at the gut mucosal level in Crohn's disease. It is likely, however, that the IFN $\gamma$ produced by intestinal lymphocytes has a central role in the inflammatory process and in the locally occurring immune phenomena in Crohn's disease.

We have shown that in Crohn's disease, as in other chronic granulomatous disease states, ${ }^{20}$ spontaneous IFN $\gamma$ production is compartmentalised. This finding and the observation that the release and synthesis of IFN $\gamma$ by lymphocytes is suppressed by corticosteroids ${ }^{27}$ and the recent report of HLA-DR molecules disappearing from the intestinal epithelium after immunosuppressive treatment ${ }^{28}$ suggest that these drugs may in part exert their known 
beneficial effect in Crohn's disease by affecting IFN $\gamma$ production in the gut mucosa.

1 Bocci C. Role of interferon produced in physiological conditions. A speculative review. Immunology 1988; 64: 1-9.

2 De Mayer E, De Mayer-Guignard J, eds. Production of IFN- $\gamma$ by $T$ cells and modulation of $T$ cells, $B$ cell and NK activity by interferons. In: Interferons and other regulatory cytokines. New York: John Wiley 1988; 221-73.

3 Johnson HM, Farrar WL. The role of gamma-interferon-like lympokine in the activation of $\mathrm{T}$ cells for expression of inmpokine in the activation of T cells for expression

4 Croll AD, Morris AG. The regulation of $\gamma$-interferon production by interleukins 1 and 2 . Cell Immunol 1986; 102: 33-42.

5 Capobianchi MR, Ameglio F, Tosi R, Dolei A. Difference in the expression and release of DR, BR and DQ molecules in human cells treated with recombinant interferon gamma: comparison to other interferons. Hum Immunol 1985; 13: 15.

6 Elson CO. The immunology of inflammatory bowel disease. In: Kirsner JB, Shorter RG, eds. Inflammatory bowel disease. 3rd ed. Philadelphia: Lea and Febiger, 1988; 97-164.

7 Pallone F, Fais S, Squarcia O, Biancone L, Pozzilli P, Boirivant $M$. Activation of peripheral and intestinal lamina propria lymphocytes in Crohn's disease. In vivo state of propria lymphocytes in Crohn's disease. In vivo state of
activation and in vitro response to stimulation as defined by the expression of early activation antigens. Gut 1987; 28: 745-53.

8 Brandtzaeg P, Halstensen TS, Kett K, et al. Physiology and immunopathology of the intestinal secretory immune system. Ital f Gastroenterol 1989; 21: 21-43.

9 Hermanowicz A, Gibson PR, Pallone F, Mason CH, Jewell DP. The function in vitro of macrophages from the intestinal mucosa of patients with Crohn's disease: an association between chemotactic migration and granulomata. $f$ Gastrobetween chemotactic migration

10 Fais S, Pallone F, Squarcia O, et al. HLA-DR antigens on colonic epithelial cells in inflammatory bowel disease. Relation to the state of activation of lamina propria lymphocytes and to the epithelial expression of other surface markers. Clin Exp Immunol 1987; 68: 605-12.

11 Pallone F, Fais S, Capobianchi MR. HLA-D region antigens on isolated human colonic epithelial cells: enhanced expression in inflammatory bowel disease and in vitro induction by different stimuli. Clin Exp Immunol 1988; 74: 75-9.

12 Pallone F, Ricci R, Boirivant M, Montano S. Measuring the activity of Crohn's disease. Ital f Gastroenterol 1981; 13: 513.

13 Harvey RF, Bradshaw JM. A simplex index of Crohn's disease activity. Lancet 1980; i: 514

14 Riddel RH. Pathology of idiopathic inflammatory bowel disease. In: Kirsner JB, Shorter RG, eds. Inflammatory bowel disease. 3rd ed. Philadelphia: Lea \& Febiger, 1988; 329-50.

15 Bull DM, Bookman MA. Isolation and functional characterization of human mucosal lymphoid cells. 7 Clin Invest 1977; 59: 966-74.

16 Stanton GJ, Langford MJ, Dianzani F. Virus yield reduction assay for interferon by titration of Sindbis virus hemagglutinin. Methods Enzymol 1981; 78: 351-7.

17 Capobianchi MR, De Marco F, Di Marco P, Dianzani F Acid labile human interferon alfa production by peripheral blood mononuclear cells stimulated by HIV-infected cells. Arch Virol 1988; 99: 9-19.

18 Lieberman BY, Fiocchi C, Youngman KR, Sapatnekar WK Proffitt MR. Interferon production by human intestina mucosal mononuclear cells. Decreased levels in inflam matory bowel disease. Dig Dis Sci 1988; 33: 1297-304.

19 Stewart WE. The interferon system. New York: Springer Verlag, 1979.

20 Robinson BWS, McLemore TL, Crystal RG. Gamma interferon is spontaneously released by alveolar macrophages and lung $\mathrm{T}$ lymphocytes in patients with pulmonary sarcoidosis. lung T lymphocytes in patients

21 Selby WS, Janossy G, Mason DY, Jewell DP. Expression of HLA-DR antigens by colonic epithelium in inflammatory bowel disease. Clin Exp Immunol 1983; 53: 614-8

22 Fais S, Pallone F. Ability of human colonic epithelium to express the 4F2 antigen, CALLA (common acute lymphoblastic leukemia antigen) and the transferrin receptor in response to different stimuli. Gastroenterology 1989; 97 : $1435-41$.

23 Cerf-Bensussan N, Quaroni A, Kurnic JT, Bhan AR. Intra epithelial lymphocytes modulate Ia expression by intestinal epithelial cells. F Immunol 1984; 132:2244-52

24 Bland PW, Warren LG. Antigen presentation by epithelial cells of the rat small intestine. I. Kinetics, antigen specificity cells of the rat small intestine. I. Kinetics, antigen specificity 25 Mayer L, Shlien R. Evidence for function of Ia molecules on gut epithelial cells in man. F Exp Med 1987; 166: 1471-83.

26 Balkwill FR. Interferons. Lancet 1989; i: 1060-3.

27 Arya SF, Wong-Staal F, Gallo RC. Dexamethasone-mediated inhibition of human $T$ cell growth factor and $\gamma$-interferon messenger RNA. F Immunol 1984; 133: 273-6.

28 Baker K, Jewell DP. Cyclosporin for the treatment of severe inflammatory bowel disease. Aliment Pharmacol Therap 1989; 3: 143-9. 